\title{
Lifetime ruin minimization: should retirees hedge inflation or just worry about it?*
}

\author{
HUAXIONG HUANG \\ Department of Mathematics and Statistics, York University, 4700 Keele Street, Toronto \\ MOSHE A. MILEVSKY \\ Schulich School of Business, York University, 4700 Keele Street, Toronto \\ (e-mail: milevsky@yorku.ca)
}

\begin{abstract}
Inflation for retirees is different from and mostly higher than the macro-economic (average) inflation rate for the entire population. In the U.S.A, for example, the Consumer Price Index for the Urban population (CPI-U) calculated and reported by the Bureau of Labor Statistics (BLS) has a lesser known cousin called the CPI-E (for the elderly) in which the sub-component weights are based on the consumption patterns of Americans above the age of 62. This suggests that Inflation-Linked Bond Funds (ILBFs) - whose individual component bond adjustments are based on broad population (CPI-U) inflation - might not be the best hedge for individual retirees' cost of living. But then again, broad shocks to inflation are likely to impact both indices. So, motivated by the question - is it good enough? - the current paper uses lifetime ruin minimization (LRM) techniques to investigate the optimal allocation between an ILBF and a nominal investment fund for a retiree facing an exogenous liability. Our model trades off the benefit of an imperfect hedge against the cost of lower investment growth. However, our numerical results suggest that although ILBFs can be a large part of the optimal retirement portfolio, it should be treated as just another asset class in the broad optimization problem as opposed to a special or unique category.
\end{abstract}

\section{Introduction and motivation}

The first American baby boomer turned 65 on 1 January 2011, with over 70 million to follow during the next 20 years. As a result, the financial services industry (in the U.S.A. and around the world) is shifting its attention from wealth accumulation to generating a sustainable retirement income. With the ongoing demise of defined benefit (DB) pensions, one of the main concerns in creating an appropriate income stream from a DC-style retirement account is the issue of inflation and price uncertainty over $25-35$ potential years of retirement.

* This research was supported in part by grants from NSERC, MITACS and the IFID Centre. The authors would like to thank Anna Abaimova, research associate at the IFID Centre during the period when this paper was written, for helpful research assistance and technical support. 
Against this backdrop, a number of financial commentators, including writers at the Wall Street Journal and the New York Times, have urged retirees to allocate a substantial portion of their retirement wealth to inflation-linked bonds, such as TIPS and I-BONDS. These investments generate periodic income in real, as opposed to nominal units. In fact, a number of large financial services companies, such as TIAA-CREF, PIMCO, Vanguard and Fidelity actively promote their inflation-linked mutual funds as a hedge against an increasing cost of living, especially for retirees. Holding a bond fund is more cost effective and feasible than holding individual TIPS.

Oddly enough, there seems to be very little discussion as to whether the Consumer Price Index for the Urban population (CPI-U) - which is the underlying adjustment mechanism for most inflation-linked bonds - is an adequate measure of the inflation rate experienced by retirees. In fact, since the early 1980s the U.S. Bureau of Labor Statistics (BLS) has been calculating an experimental index called the CPI-E, for Americans above the age of 62 . This index weights its expenditure sub-components based on the spending habits of the elderly, as opposed to the aggregate (urban dwelling or wage earning) population. See Amble and Stewart (1994) or Hobijn and Lagakos (2003) for more statistical and methodological details about this experimental index. The index was motivated by a group of legislators within the U.S. House of Representatives who wanted to introduce an alternative inflation index for retirees, one that could be used to better adjust Social Security payments, see House of Representatives (2001). Currently, Social Security payments in the U.S.A. are adjusted each year based on the previous year's inflation rate as measured by the CPI-W, which is a sub-component of the CPI-U. ${ }^{1}$

Figure 1 all tables and charts are placed in the appendix exhibits the annualized gap between the CPI-E (elderly) versus the CPI-U (urban, used to adjust inflation-linked bonds) during the last 25 years. On average the gap is positive, by approximately 50 basis points per annum, which implies that the CPI-E increases at a greater rate, compared with the CPI-U. If both of these indices moved in lock-step, the gap would obviously be zero.

The reason for this out performance - or excessive inflation rate - is that retirees have different consumption and spending habits compared with the general population. They spend more of their disposable income on medical care and housing, and of course these prices have increased more than other subcomponents during the last 25 years. Whether this will persist going forward, especially after the 2007/2008 decline in housing prices is debatable. But, once again, our agenda is not to forecast inflation but to alert readers to the implications of different inflation rates for different groups on optimal asset allocation. Table 1 displays the relative importance and

${ }^{1}$ We obviously don't want to get caught-up in the minutia of inflation measurement and forecasting. Technically though, the CPI-W is for a representative household where more than one-half of the household's income must come from clerical or wage occupations and at least one of the household's earners must have been employed for at least 37 weeks during the previous 12 months. The CPI-W's population represents about 32 percent of the total U.S. population and is a subset or part of the CPI-U's (which stands for Urban) population. The CPI-U is used for computing the coupons and inflationadjustments on Treasury Inflation Protection Securities (TIPS) as well as I-Bonds. From a practical perspective the CPI-W and the CPI-U are much closer to each other in composition, relative to the experimental CPI-E. 
Table 1. Components of the CPI, wage-earners $(W)$ versus urban $(U)$ versus elderly $(E)$

\begin{tabular}{lccc}
\hline \hline Spending on & \% of CPI-W & \% of CPI-U & \% of CPI-E \\
\hline Apparel & 3.57 & 3.86 & 2.42 \\
Education and communication & 5.97 & 5.51 & 3.19 \\
Food and beverage & 15.10 & 16.56 & 12.87 \\
Housing & 42.24 & 39.96 & 47.51 \\
Medical care & 6.35 & 5.27 & 10.81 \\
Recreation & 5.38 & 4.84 & 4.62 \\
Transportation & 17.95 & 20.37 & 14.99 \\
Other goods and services & 3.45 & 3.64 & 3.59 \\
Total & 100 & 100 & 100 \\
\hline \hline
\end{tabular}

These weights are computed and selected by the BLS, disclosed in April 2008. Note that weights vary over time based on the consumer expenditure survey conducted by the BLS and with inflation adjustments.

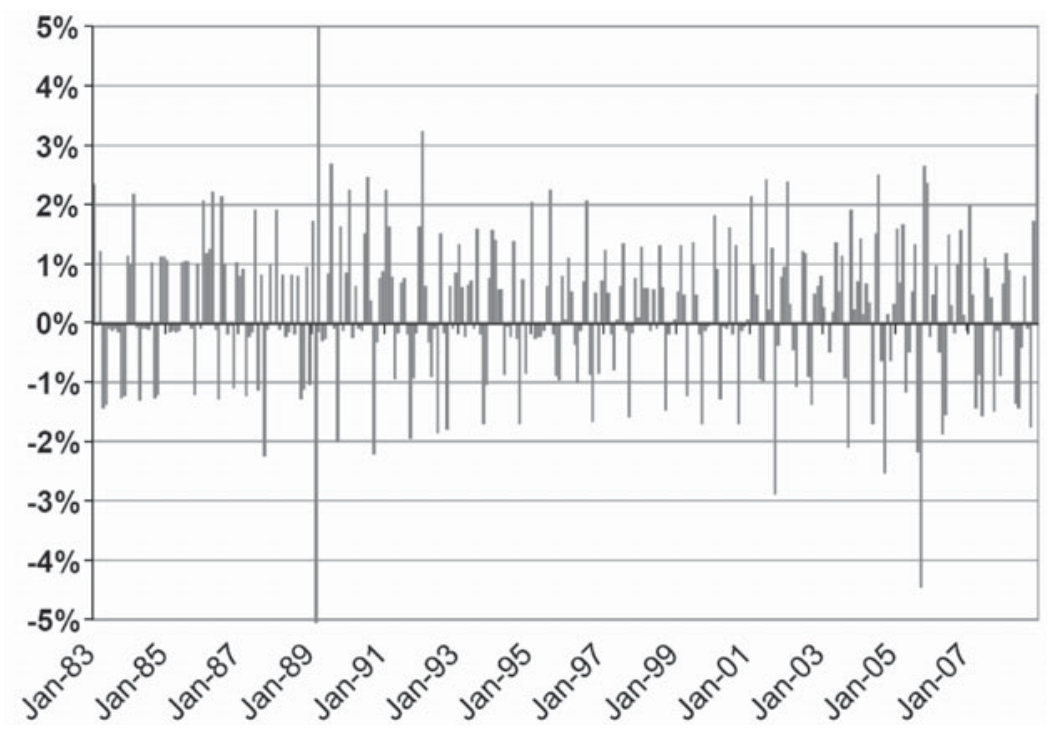

Figure 1. Annualized gap: CPI-E inflation minus CPI-U inflation.

weights of the major expenditure categories in the respective indices. Note that medical care is weighted $10.81 \%$ in the CPI-E but only $5.27 \%$ in the CPI-U, for example. Likewise, food is $12.87 \%$ in the CPI-E but is $16.56 \%$ higher in the CPI-U. Needless to say, any financial instrument - such as inflation-linked bond funds (ILBFs) - whose returns are linked to the CPI create an imperfect hedge for a typical retiree's personal inflation rate.

Figure 2 illustrates the extent to which the investment returns from holding an ILBF might differ from changes (or shocks) to the inflation rate for the elderly. 


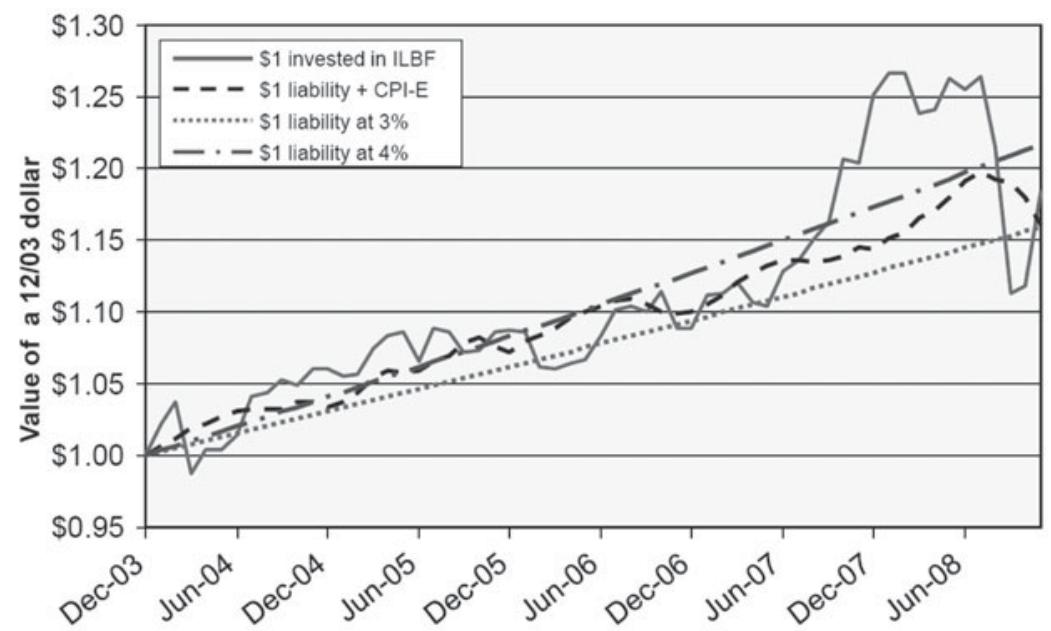

Figure 2. Values of $\$ 1$ invested ILBF* versus the nominal value of an adjusted $\$ 1$ liability. *Based on the average returns of four ILBFs.

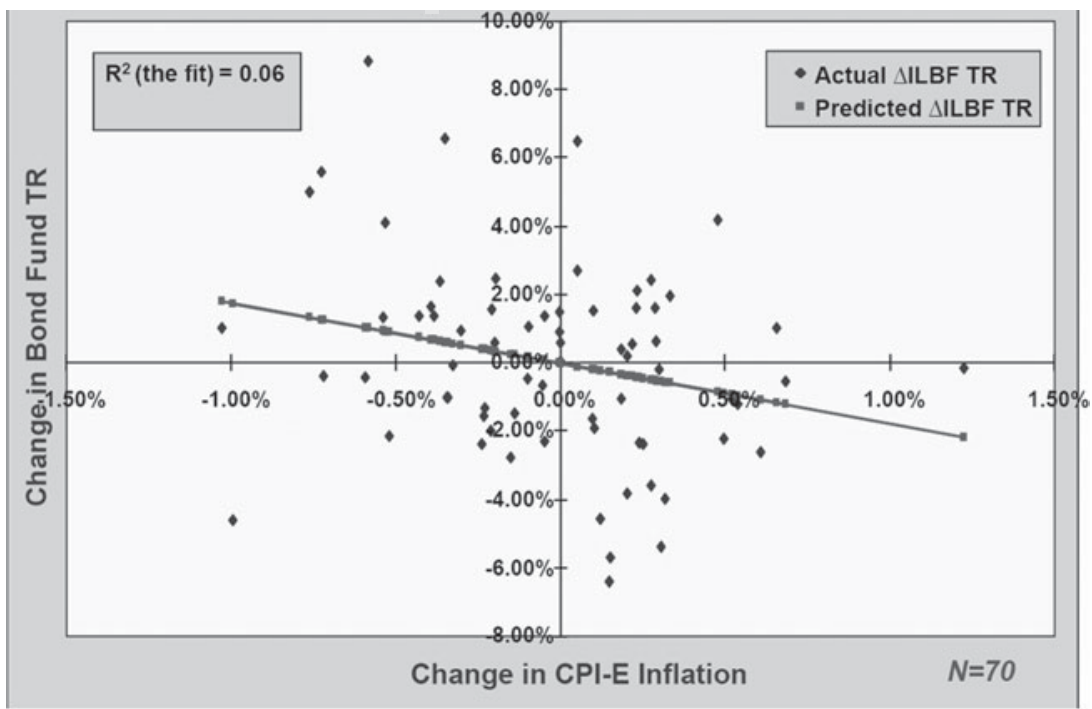

Figure 3. The fit. Changes in CPI-E versus changes in inflation- linked bond fund total return monthly periods from $12 / 02$ to $11 / 08$.

It displays the ongoing market value of $\$ 1$ invested in a hypothetical ILBF in December 2003, as well as the total change in the CPI-E starting from December 2003. Two additional curves were traced in Figure 2, showing a constant rate of $3 \%$ and $4 \%$ applied to the initial $\$ 1$ investment. This hypothetical fund was constructed (by the authors) by averaging the monthly total returns the four most popular ILBFs available to retail investors in the U.S.A. (they are T. Rowe, Fidelity, TIAA CREF and Vanguard). In other words, at the end of the month the portfolio was rebalanced so 
that $25 \%$ was held in each of the four ILBFs. Note how the value of this investment increases over time, somewhere between $3 \%$ and $4 \%$ per year, but is more volatile and often falls outside this range. In contrast, the CPI-E-adjusted value of the initial \$1 stays within this 3-4\% band.

Figure 3 takes this analysis one step further. It displays the results from regressing the monthly returns from the above-mentioned hypothetical portfolio of ILBFs against the changes in the unique CPI for the elderly. If the fit was perfect, the points would all fall on a $45^{\circ}$ line. Clearly, this is not the case. The $R^{2}=0.06$, which is an estimate we will use later in our (continuous time) model. We do not have enough data points to conduct a statistically significant analysis for (the lower frequency) annual returns, although the $R^{2}$ is higher over longer return windows, as one would expect. On the other hand, we should note that when the analysis underlying Figure 2 and/or Figure 3 is conducted for any of the individual ILBFs, as opposed to the hypothetical average of the four - which diversifies the holder further against risks - the results are even more pronounced. More importantly, each individual retiree will have their own desired weightings for consumer expenditures, which might further reduce the correlations between their cost of living (e.g., CPI-ME) and aggregate inflation. Thus, although any given ILBF (or inflation-adjusted pension) is expected to increase over time as general prices increase, it is important not to confuse an investment that increases over time with an investment that provides perfect insurance against individual-specific shocks.

Once again, we are not the first to point out that personal inflation rates are distinct from macro-economic inflation measures, especially as it pertains to retirees. Just as an example, a group of well-known economists, Ernst et al. (1997) used a unique dataset of prescription drug prices to focus on the challenges of measuring inflation for retirees. In fact, some researchers - such as Jennings (2006), or Aziz et al. (2001) - have argued that as a result of these imperfect measures, CPI-linked bonds (which are the building blocks of ILBFs) should be disaggregated into individual sub-components so that consumers can reconstruct the bonds using their preferred weights. In this way, a suitably tailored bond fund would generate payments and provide income based on a rate that is linked to the medical care component of the CPI, for example. Retirees and for that matter any consumer with a basket of consumption that differs from the general CPI, would be able to pick and choose their own ILBF that would hedge their own inflation rate.

And, while this idea is great in theory, consumers and current retirees, who are still waiting for access to this engineering innovation, must contend with a generic ILBF that is weakly correlated to their desired consumption's cost of living adjustments. The pragmatic question is: How much wealth should they allocate to an imperfect insurance policy? Are they better off taking their chances on a long-run equity risk premium - or balanced stock/bond fund-that is expected to grow their portfolio over time?

This is the impetus for our paper. In the real-world absence of a perfect hedge, we gauge whether retirees are better-off investing in an asset class that is expected to grow over time - such as a diversified mutual fund - versus investing in an asset class that may (or may not) hedge a retiree's cost of living. We develop a model that 
illustrates how the correlation or lack thereof, between ILBF and a retiree's personal inflation rate impacts the demand and optimal allocation to this asset.

\subsection{Our position within the literature}

Most 'lifecycle choice' models are built and calibrated assuming the consumer seeks to maximize their end-of-period utility of wealth or their ongoing utility of consumption under a variety of risk-aversion parameters and inter-temporal rates of substitutions. This approach to the dynamic asset allocation problem was initiated by Merton (1971) and has spawned hundreds and possibly thousands of papers using these techniques. See Campbell and Viciera (2002) for an extensive literature review. A recent monograph by Ibbotson et al. (2007) takes the same utilitybased approach as well. In related literature, Kothari and Shanken (2004) derive an optimal asset allocation with inflation-linked bonds, although not within the context of a retiree facing exogenous liabilities. We do use a number of their parameter estimates for our inputs, but differ in methodology and objective. The 'calibrating' asset allocation literature continues to grow, and due to the lack of space for a comprehensive literature review we refer the interested reader to recent papers by Horneff et al. (2008) or Hoevenaars et al. (2008) as well as Cairns et al. (2006).

Our primary model, however, is predicated on a retiree who seeks to minimize the probability of lifetime ruin, assuming that their expenditures are stochastic (but exogenous) in nominal terms. The lifetime ruin minimization (LRM) framework has been adopted or discussed in a number of recent papers. Examples within this literature include the original paper by Browne (1995) with a deterministic horizon, Milevsky and Robinson (2000) in a static framework with a stochastic horizon, Albrecht and Maurer (2002), Young (2004) in a dynamic framework, Moore and Young (2006), Bayraktar and Young (2007) as well as the recent working paper Robinson and Tahani (2007). More broadly, our paper is related to Gupta and Li (2007) and Haberman and Vigna (2002). In all these articles, normative models are proposed for individuals as they transition into retirement under a variety of objective functions. They do not necessarily maximize discounted utility of lifetime consumption, a la Merton (1971), but instead use a framework that eliminates the need for requiring subjective discount rates and/or coefficients of relative risk aversion. The LRM approach resonates with some fraction of the wealth management community, which is one of the reasons why we have adopted it as a framework for this analysis. More importantly, by stripping away time, risk and substitution preferences we are able to directly measure the impact of not having a perfect hedge on the probability of success and the affordability of a given projected liability. Our paper is also related to recent work by Wang (2009) and Gao (2009) in that we also use the HamiltonJacobi-Bellman (HJB) formulation and techniques to analyze and extract the ruin probability from a retirement income perspective. From a methodological point of view the contribution of this paper is to extend the existing literature on ruin-minimizing optimal control to the case where there are three - as opposed to just one - state variables, in an incomplete market. 
The additional level of complexity eliminates the ability to derive analytic solutions and expressions for the optimal control, since we are left with a collection of PDEs. Our paper provides numerical results that help shed light on the optimal demand for CPI-linked bonds, by retirees who are concerned with a simple objective function: minimizing the probability of running out of money before running out of life.

The remainder of this paper is organized as follows. Section 2 develops our underlying optimization model. Section 3 presents the derivation of the HJB equation satisfied by the ruin probability and methodologies for solving the equation. Section 4 provides numerical examples and displays relevant results. Section 5 concludes the paper and in the appendix more technical details are provided.

\section{The underlying model}

Consistent with the LRM references cited above, our model retiree starts with initial (nest egg) wealth denoted by $W_{0}=w$, from which he/she spends at a rate of $\$ 1$ per annum, initially. Practitioners refer to this as an inial spending rate of $1 / w$. We assume that the retiree's exogenous liabilities or the annual rate of desired consumption - measured in nominal terms - evolve according to the diffusion process:

$$
\mathrm{d} L_{t}=\pi L_{t} \mathrm{~d} t+\xi L_{t} \mathrm{~d} B_{t}^{\pi}, \quad L_{0}=1,
$$

where the parameter $\pi$ is the expected cost-of-living adjustment (COLA), which is unique to the retiree, $\xi$ is the volatility rate and $B_{t}^{\pi}$ is the Brownian motion driving the uncertainty COLA uncertainty. For example, a retiree might expect his or her spending will increase by $\pi=4 \%$ each year, with a volatility of $\xi=3 \%$. Think of this as a personal inflation index/rate. Figure 2 - displayed earlier - represents one possible sample path of $L_{t}$ from the December/03 to December/08 period.

In our simple model, the retiree's net worth of $W_{0}=w$ can be allocated between two types of investment funds. The first is a lower-risk ILBF that evolves according to the diffusion process:

$$
\mathrm{d} I_{t}=r I_{t} \mathrm{~d} t+\eta I_{t} \mathrm{~d} B_{t}^{r}, \quad I_{0}=1,
$$

where $r$ is the expected return - in nominal terms - and $\eta$ is the volatility. In this case $B_{t}^{r}$ denotes the Brownian motion driving the ILBF. It is important to emphasize that $I_{t}$ does not represent the price of a particular CPI-linked bond, nor does it represent a coupon rate. Rather, one can best think of $I_{t}$ as a unit value of a mutual fund ${ }^{2}$ that invests in a collection of CPI-linked bonds across various maturities, where all coupons and maturity payments are re-invested in the fund. Figure 2 also presents a possible sample path for $I_{t}$, over the same December/03 to December/08 period. It was clearly more volatile than $L_{t}$, and had a low correlation, as per Figure 3 . Typical parameter values could be an expected $r=5$ nominal investment return, which would consist of 2 real-return and perhaps 2.5 inflation and a 0.5 inflation risk premium, although the exact decomposition is completely unnecessary for our analysis.

\footnotetext{
${ }^{2}$ We obviously do not attempt to offer or develop a complete model that prices all CPI-linked bonds in the most advanced term-structure sense. For something along those lines, we refer interested readers to Jarrow and Yildirim (2003) for example. We are focused on a basic portfolio of CPI-linked bonds within a mutual fund structure.
} 
The typical volatility $\eta$ would be in the $8 \%$ range. These numbers are consistent with Ibbotson Associates estimates of the long-run volatility of a typical CPI-linked mutual fund, again in nominal terms.

The second investment alternative is an equity-based investment mutual fund that evolves according to the diffusion process:

$$
\mathrm{d} Y_{t}=\mu Y_{t} \mathrm{~d} t+\sigma Y_{t} \mathrm{~d} B_{t}^{y}, \quad Y_{0}=1,
$$

where $\mu$ is the expected nominal return and $\sigma>0$ is the volatility of the risky fund. Typical parameter values are between $6 \%$ and $11 \%$ for the expected fund return $\mu$ and $10 \%-30 \%$ for the fund volatility $\sigma$. Nothing is new here.

The correlation structure between the Brownian motions driving the uncertainty is as follows. First, the correlation between $B_{t}^{\pi}$ (driving the retiree's personal inflation rate or COLA) and $B_{t}^{r}$ (driving the ILBF), is relatively high but not $100 \%$. It is denoted by $\rho_{\pi r}$. Likewise, the correlation between $B_{t}{ }^{\pi}$ and $B_{t}^{y}$ (the mutual fund) is obviously lower than $\rho_{\pi r}$, and will be denoted by $\rho_{\pi y}$. Finally, the correlation between $B_{t}^{y}$ and $B_{t}^{r}$ is denoted by $\rho_{r y}$. Visually, the correlation structure is as follows:

$$
\mathbf{L}_{t}(\mathrm{COLA}) \quad \mathbf{I}_{t} \text { (ILBF) } \quad \mathbf{Y}_{t} \text { (Stocks) }
$$

\begin{tabular}{|c|c|c|}
\hline 1 & $\rho_{\pi r}$ & $\rho_{\pi y}$ \\
\hline$\rho_{\pi r}$ & 1 & $\rho_{r y}$ \\
\hline$\rho_{\pi y}$ & $\rho_{r y}$ & 1 \\
\hline
\end{tabular}

which - to be invertible - imposes some natural conditions on the relationship between the three available correlations, which we will address later. In terms of calibration, Kothari and Shanken (2004) estimated the correlation between equity market returns and (hypothetical) CPI-linked funds returns is close to zero, so that $\rho_{r y} \approx 0$. For the most part, we will use this parameter estimate in our numerical examples. Likewise, the correlation $\rho_{\pi r}$ between the CPI-linked fund and the retiree's COLA is a matter of debate - and the core concern within our paper - so we will use two extreme cases; the first being a low correlation of $40 \%$ and the second being a high correlation of $95 \%$. Finally, the correlation between the investment fund and the liabilities is partially constrained by the invertability of the correlation matrix (4), which we discuss later.

Putting all this together, the dynamics for the retiree's investment portfolio will obey:

$$
\mathrm{d} W_{t}=\alpha_{t} W_{t} \frac{\mathrm{d} I_{t}}{I_{t}}+\left(1-\alpha_{t}\right) W_{t} \frac{\mathrm{d} Y_{t}}{Y_{t}}-L_{t} \mathrm{~d} t, \quad W_{0}=w,
$$

where $\alpha_{t}$ is the fraction of the portfolio that is allocated to the ILBF and $\left(1-\alpha_{t}\right)$ is the fraction allocated to the investment or equity-based mutual fund. Again, $L_{t}$ is defined as the consumption rate, i.e., consumption per unit of the time and is assumed exogenous as opposed to optimized. 
With the LRM approach, the retiree's problem is to minimize the probability of ruin over a retirement horizon $T=\infty$, but with a random time of death $\tau_{\mathrm{d}}$, under a given law of mortality. The infinite horizon might sound odd in the context of a human life, but obviously the force of mortality will eventually kill the retiree well before $T=\infty$. So in some sense it is just a technicality. Also, the uncertainty in the length of human life can be hedged using pension annuities and our model can always be framed in terms of the choice between CPI-linked payout annuities and marketlinked variable annuities. In other words, irrespective of whether they pose the problem as optimal allocations to non-annuitized investments or to income annuities, the underlying issue is the same.

Formally, the objective function can be stated as

$$
\phi(w, l, t)=\min _{0 \leqslant \alpha_{t} \leqslant 1} \operatorname{Pr}\left[\tau_{0}<\tau_{\mathrm{d}} \mid W_{t}=w, L_{t}=l, \tau_{\mathrm{d}}>t\right],
$$

where $\tau_{0}$ is the time at which $W_{t}$ first becomes zero. The additional constraint $\alpha_{t} \geqslant 0$ is imposed to preclude any short positions in the ILBF and $\alpha_{t} \leqslant 1$ is imposed to preclude any leveraged position. Our technical objective is to locate the optimal control $\alpha_{t}^{*}(w, t)$ as a function of the drift and diffusion parameters $\mu, \sigma, \pi, \xi, r, \eta$ as well as the correlation parameters $\rho_{\pi r}, \rho_{\pi y}$ and $\rho_{r y}$. As we have stated earlier, we are particularly interested in how $\alpha_{t}^{*}(w, t)$ varies with respect to changes in the correlation $\rho_{\pi r}$ between the CPI and retiree's COLA or personal inflation rate.

Before we proceed to solve for the optimal control and the corresponding minimal ruin probability, we note the following. The qualitative interpretation of $\xi=0$ is that the retiree's consumption liabilities will not fluctuate in nominal terms, although they can certainly fluctuate in CPI-adjusted terms. Likewise, the interpretation of $\eta=0$ is that the ILBF grows deterministically over time at a rate or $r$, which means that there is no CPI risk in the system. Finally, when both $\xi=0$ (i.e., no liability volatility) and $\eta=0$ (no CPI risk), our problem boils down to minimizing the probability of ruin in a complete market, which most recently was examined by Moore and Young (2006). Keep in mind, however, that the absence of any risk-free asset in either nominal or personal-inflation adjusted terms, implies that the retiree can never reduce the ruin probability $\phi(w, t)$ to zero by immunizing (e.g., annuitizing) the consumption liability stream. The problem boils down to an economic trade-off between: (i) investing retirement wealth in an asset $Y_{t}$ that is expected to earn $\mu>\pi$, and is greater than the projected increase in the retiree's cost of living, and (ii) investing in the relatively safe (and highly correlated) asset $I_{t}$, which is not expected to earn as much as $Y_{t}$, since $r<\mu$. Hence, the title of this paper, should retirees insure against their inflation rate by allocating a substantial portion of their wealth to an imperfect hedge or should they just 'worry' about it, and instead invest more aggressively.

\section{The HJB equation}

In this paper, we use Gompertz mortality for the hazard rate and the time variable is equivalent to biological age. The ruin probability satisfies the following HJB 
equation:

$$
\lambda_{a} \psi=\psi_{a}+\min _{0 \leqslant \alpha \leqslant 1} H
$$

where

$$
\begin{aligned}
H:= & \frac{1}{2}\left\{\left[\alpha^{2} \eta^{2}+(1-\alpha)^{2} \sigma^{2}+2 \alpha(1-\alpha) \rho_{r y} \eta \sigma\right]+\xi^{2}-2\left[\alpha \rho_{\pi r} \eta+(1-\alpha) \rho_{\pi y} \sigma\right] \xi\right\} x^{2} \psi_{x x} \\
& +\left\{[\alpha r x+(1-\alpha) \mu x-1-\pi x]+\xi^{2} x-\left[\alpha \rho_{\pi r} \eta+(1-\alpha) \rho_{\pi y} \sigma\right] \xi x\right\} \psi_{x},
\end{aligned}
$$

with boundary conditions

$$
\psi(0, a)=1, \quad \psi(\infty, a)=0, \quad \psi(x, \infty)=0 .
$$

Here we collapse $w$ and $l$ into a single variable $x=w / l$ with $\psi(x, a)=\phi(w, l, a)$, and reduce the dimension of the HJB by one. The detailed derivation can be found in the appendix.

On a related note, when the investment portfolio consists of a risk-free asset and consumption rate is a constant, it can be shown that the ruin can be avoided under certain conditions, and the probability of ruin, when it is not zero, is a convex function of the wealth, as shown by Young (2004). However, the situation considered in this paper is more complicated. When the liability and the risky assets are completely correlated, it is possible to avoid ruin when the wealth level is sufficiently high. On the other hand, when the risky assets and liability are not perfectly correlated, the probability of ruin is no longer a convex function of wealth. This adds an additional complexity to the solution procedure. We refer the readers to the appendix for more details.

\section{Numerical solutions and examples}

\subsection{Parameter values}

Before we present the results we provide the rationale for the choice of relevant parameter values. The first risky asset $Y_{t}$, is a classical investment mutual fund that is expected to earn a nominal $\mu$ between $6 \%$ and $11 \%$ with a volatility of $\sigma=20 \%$. The second risky asset is the ILBF $I_{t}$, whose expected (nominal) return is $r=5 \%$ with a volatility of $\eta=8 \%$. In most of our numerical examples we assume that the two risky assets (ILBF and equity/stock fund) are uncorrelated (even though our methodology can readily handle any correlation between the two). In fact, one of the benefits of using two uncorrelated assets is that this deliberately biases our results away from investing in the equity-based fund $Y_{t}$ as a hedge against the retiree's liabilities.

The retiree starts with a consumption liability rate of $L_{0}=\$ 1$ per year at retirement but at a varying level of initial wealth $W_{0}$, allocated among $Y_{t}$ and $I_{t}$. The retiree withdraws a stochastic $L_{t}, t>0$ per year. As discussed within the derivation, we assume that $0 \leqslant \alpha_{t} \leqslant 1$, and thus prohibit leverage and short sales. We assume that $L_{t}$ increases by $\pi=4 \%$ per annum, under two separate cases: volatility of $\xi=3 \%$ (high) 
and $1 \%$ (low). We assume that the CPI-linked fund has a higher expected return $r$, relative to the liabilities and with greater volatility $\eta=8 \%$. Ultimately, we are interested in the minimal probability of ruin assuming the correlation between liabilities $L_{t}$ and bond funds returns $I_{t}$ is $\rho_{\pi r}=95 \%$ (high) and $40 \%$ (low). Moreover, we are interested in how the decreasing return of the equity-based asset will force a greater allocation to the bond fund. We are also interested in the minimal ruin probability as a function of the correlation between the CPI-based bond fund and the consumption liability $\rho_{\pi r}$. The value of the remaining correlation coefficient is taken to be $\rho_{\pi y}=0.25$, which is chosen so that the positivity of the correlation matrix is guaranteed.

All the computations are carried out with an initial retirement age of $a=65$ and a time horizon of $T=60$ (a maximum age of 125). We have experimented with a longer time horizon and the results are virtually identical, since obviously the retiree dies well before $T=60$. We used the so-called Gompertz mortality rate in the numerical results, which implies that the actuarial force of mortality satisfies the following equation:

$$
\lambda_{a}=\lambda_{0}+\frac{1}{b} \exp \left(\frac{a-m}{b}\right)
$$

The hazard/mortality rates become sufficiently large for a large $T$, so the survival rate is negligible after 125 years of life. For the result we displayed, we used the set of parameter values: $m=86.3, b=9.5$ and $\lambda_{0}=0.003$. The source of these numbers is Milevsky (2006). Also, to carry out the computations, we have replaced the infinite domain $0 \leqslant x<\infty$ by a finite one $0 \leqslant x \leqslant x_{\max }$. We found that as long as $x_{\max }$ is sufficiently large, the effect on the solution is small. We have chosen $x_{\max }=200$. This is equivalent to assuming that the ruin probability is zero when the wealth to liability ratio is 200 . A total of 1,000 grid points are used for the state variable $x=w / l$ and 240 time steps in time. We also experimented with larger number of grid points in $x$ and $a$, and almost identical results were obtained. Finally, we have also compared the solutions obtained by explicit and implicit methods. Again, the results are virtually the same.

\subsection{Cases and examples}

In Table 2, we present the numerically computed values of the minimum ruin probability and the asset allocation percentage $\alpha^{*}$ for a high correlation $\rho_{\pi r}=95 \%$ between (shocks to) the COLA and (innovations to) the CPI-linked fund, together with a high volatility for the consumption liability $\xi=3 \%$. We are interested in the interaction of the assumed equity return $\mu$ and the initial spending rate $1 / w$.

Here is how to interpret the results. A 65-year-old retiree with initial investment wealth (nest egg) of $\$ 1,000,000$ wants to spend/consume $\$ 40,000$ per year adjusted for personal inflation. In the language of our model, this is a desired spending rate of $4 \%$ and is equivalent to an initial wealth to consumption ratio of $W_{0}=25$. The retiree estimates that this liability $L_{t}$ will increase on average by $\pi=4 \%$ per year (using continuous compounding) with a volatility of $\xi=3 \%$. The retiree has a choice of 
Table 2. Optimal allocation to ILBF assuming high (95\%) correlation with personal inflation

\begin{tabular}{|c|c|c|c|c|c|c|c|c|}
\hline \multirow{3}{*}{$\begin{array}{l}\text { Expected } \\
\text { Investment } \\
\text { Fund return }(\%)\end{array}$} & \multicolumn{2}{|c|}{$W_{0}=18$} & \multicolumn{2}{|c|}{$W_{0}=20$} & \multicolumn{2}{|c|}{$W_{0}=22$} & \multicolumn{2}{|c|}{$W_{0}=25$} \\
\hline & \multicolumn{2}{|c|}{ Spend $=5.5 \%$} & \multicolumn{2}{|c|}{ Spend $=5.0 \%$} & \multicolumn{2}{|c|}{ Spend $=4.54 \%$} & \multicolumn{2}{|c|}{ Spend $=4.0 \%$} \\
\hline & $\alpha^{*}$ & $\psi$ & $\alpha^{*}$ & $\psi$ & $\alpha^{*}$ & $\psi$ & $\alpha^{*}$ & $\psi$ \\
\hline$\mu=6$ & 0 & 0.478 & 0.300 & 0.407 & 0.541 & 0.339 & 0.726 & 0.244 \\
\hline$\mu=7$ & 0.076 & 0.430 & 0.306 & 0.359 & 0.477 & 0.293 & 0.642 & 0.205 \\
\hline$\mu=8$ & 0.127 & 0.378 & 0.312 & 0.307 & 0.453 & 0.244 & 0.599 & 0.165 \\
\hline$\mu=9$ & 0.165 & 0.324 & 0.323 & 0.256 & 0.445 & 0.197 & 0.576 & 0.126 \\
\hline$\mu=10$ & 0.201 & 0.271 & 0.339 & 0.206 & 0.447 & 0.153 & 0.564 & 0.093 \\
\hline$\mu=11$ & 0.233 & 0.219 & 0.357 & 0.160 & 0.454 & 0.114 & 0.560 & 0.065 \\
\hline
\end{tabular}

Note: Assets that are not invested in the ILBF are allocated to Equity Fund with mean return $\mu$, and volatility $\sigma=20 \%$. The expected return from ILBF is $r=5 \%$, with volatility $\eta=8 \%$. Correlation between ILBF and Equity Fund return is $\rho_{r v}=0 \%$. Correlation between personal inflation and Equity Fund return is $\rho_{\pi y}=25 \%$. Note that there is a constraint on the third correlation figure, $\rho_{\pi y}$ needed for the positivity of the covariance matrix. For $\rho_{r y}=0$ and $\rho_{\pi r}=0.95$, we find that $\rho_{\pi y}<31.225 \%$. In the computations, we have chosen $\rho_{\pi y}=25 \%$. All these numbers are consistent with - although not identical to - the Ibbotson Associates estimates for the behavior of TIPS-based funds, which invest in long-maturity CPI-linked bonds. The underlying model assumes the retiree starts with $W_{0}$ in liquid assets and spends $L_{0}=1$ per year, which increases by an expected $\pi=4 \%$ with a volatility of $\xi$ per year. The column headed by $\alpha^{*}$ denotes the optimal allocation and the column headed by $\psi$ denotes the minimum ruin probability.

High $\left(\rho_{\pi r}=95 \%\right)$ correlation with personal inflation rate

High $(\xi=3 \%)$ volatility of personal inflation rate; expected $\pi=4 \%$

investing wealth between a CPI-linked mutual fund that is expected to earn $r=5 \%$ per year with a volatility of $\eta=8 \%$ and a riskier equity (or balanced) fund. The investment fund has a volatility of $\sigma=20 \%$ and the expected return is denoted by $\mu$. Tables 2 and 3 display the optimal allocation to the CPI-linked fund depending on the retiree's subjective estimate of the expected return $\mu$. For example, if the equity (balanced) fund is expected to earn a mere $\mu=6 \%$, which is 100 basis points more than the CPI-linked fund, the initial optimal allocation to the CPI-linked fund is $72.6 \%$. The other $27.4 \%$ is allocated to the equity fund. Obviously, since the expected return $\mu$ from the equity fund is low the majority of the nest egg should rationally be placed in the CPI-linked fund. In this case, under the optimal strategy, the lifetime probability of ruin is $24.4 \%$. This, recall, is the lowest possible ruin probability - from the set of all possible dynamic investment strategies - given the specified parameters. Now, if the retiree expects the return on the equity fund to be $\mu=11 \%$, which is 500 basis points higher than the previous example, then the optimal allocation of the CPI-linked fund is a (much) lower than $56 \%$. This means that $64 \%$ should be allocated to equity. Naturally, if one is more optimistic about equity $(\mu)$, the optimal allocation is greater. In this case, the minimal ruin probability is a mere $6.5 \%$ as opposed to $24.4 \%$. 
Table 3. Optimal allocation to ILBF assuming low (40\%) correlation with personal inflation

\begin{tabular}{|c|c|c|c|c|c|c|c|c|}
\hline \multirow{3}{*}{$\begin{array}{l}\text { Expected } \\
\text { Investment } \\
\text { Fund return ( \%) }\end{array}$} & \multicolumn{2}{|c|}{$W_{0}=18$} & \multicolumn{2}{|c|}{$W_{0}=20$} & \multicolumn{2}{|c|}{$W_{0}=22$} & \multicolumn{2}{|c|}{$W_{0}=25$} \\
\hline & \multicolumn{2}{|c|}{ Spend $=5.5 \%$} & \multicolumn{2}{|c|}{ Spend $=5.0 \%$} & \multicolumn{2}{|c|}{ Spend $=4.54 \%$} & \multicolumn{2}{|c|}{ Spend $=4.0 \%$} \\
\hline & $\alpha^{*}$ & $\psi$ & $\alpha^{*}$ & $\psi$ & $\alpha^{*}$ & $\psi$ & $\alpha^{*}$ & $\psi$ \\
\hline$\mu=6$ & 0.089 & 0.479 & 0.435 & 0.408 & 0.624 & 0.340 & 0.735 & 0.249 \\
\hline$\mu=7$ & 0.143 & 0.432 & 0.366 & 0.361 & 0.517 & 0.296 & 0.645 & 0.212 \\
\hline$\mu=8$ & 0.164 & 0.381 & 0.341 & 0.311 & 0.468 & 0.249 & 0.590 & 0.172 \\
\hline$\mu=9$ & 0.185 & 0.328 & 0.334 & 0.260 & 0.444 & 0.203 & 0.556 & 0.135 \\
\hline$\mu=10$ & 0.206 & 0.275 & 0.337 & 0.211 & 0.434 & 0.159 & 0.535 & 0.101 \\
\hline$\mu=11$ & 0.229 & 0.223 & 0.344 & 0.166 & 0.431 & 0.120 & 0.523 & 0.072 \\
\hline
\end{tabular}

Note: Assets that are not invested in the ILBF are allocated to Equity Fund with mean return $\mu$, and volatility $\sigma=20 \%$. The expected return from ILBF is $r=5 \%$, with volatility $\eta=8 \%$. Correlation between ILBF and Equity Fund return is $\rho_{r y}=0 \%$. Correlation between personal inflation and Equity Fund return is $\rho_{\pi y}=25 \%$. Note that the third correlation figure, $\rho_{\pi y}<91.66 \%$ is forced by the two other values $\rho_{r y}=0$ and $\rho_{\pi r}=0.40$. For consistency, we have chosen the same value as before, $\rho_{\pi y}=25 \%$.

Low $\left(\rho_{\pi r}=40 \%\right)$ correlation with personal inflation rate

High $(\xi=3 \%)$ volatility of personal inflation rate; expected $\pi=4 \%$

Table 4. Optimal allocation to ILBF

\begin{tabular}{|c|c|c|c|c|c|c|c|c|c|}
\hline \multirow{4}{*}{$\begin{array}{l}\text { Expected } \\
\text { Investment } \\
\text { Fund return }(\%)\end{array}$} & \multicolumn{9}{|c|}{ Assuming $W_{0}=33.3$, initial spending rate of $1 / 33.3=3 \%$} \\
\hline & \multicolumn{3}{|c|}{$\rho_{\pi r}=0.25$} & \multicolumn{3}{|c|}{$\rho_{\pi r}=0.50$} & \multicolumn{3}{|c|}{$\rho_{\pi r}=0.95$} \\
\hline & \multicolumn{3}{|c|}{ Volatility $\sigma$} & \multicolumn{3}{|c|}{ Volatility $\sigma$} & \multicolumn{3}{|c|}{ Volatility $\sigma$} \\
\hline & 10 & 15 & 20 & 10 & 15 & 20 & 10 & 15 & 20 \\
\hline$\mu=6$ & 0.485 & 0.686 & 0.795 & 0.521 & 0.707 & 0.808 & 0.590 & 0.746 & 0.832 \\
\hline$\mu=8$ & 0.365 & 0.577 & 0.710 & 0.410 & 0.604 & 0.728 & 0.503 & 0.660 & 0.763 \\
\hline$\mu=10$ & 0.325 & 0.520 & 0.654 & 0.377 & 0.552 & 0.676 & 0.486 & 0.621 & 0.721 \\
\hline
\end{tabular}

Cost of living to increase by $\pi=4 \%$ per year, with a volatility of $\xi=3 \%$. Expected return from the ILBF is $r=5 \%$ per annum with a volatility of $\eta=8 \%$. The correlation between the equity fund and the ILBF is $\rho_{r y}=0 \%$. Correlation between the liability and the investment fund is $\rho_{\pi y}=25 \%$. This table examines the low $(3 \%)$ spending rate case.

All the numbers in Table 2 assume that the correlation between the (shocks to) retirement liabilities $L_{t}$ and the CPI-linked fund returns is quite high, at $\rho_{\pi r}=95 \%$. To contrast this case, in Table 3 we display the results of the minimum ruin probability $\psi$ and optimal asset allocation percentage $\alpha^{*}$ for a lower correlation value of $\rho_{\pi r}=40 \%$ between the personal inflation rate shocks and the returns to the CPIlinked fund. We still assume the (high) volatility of personal inflation, $\xi=3 \%$. In this 
case, notice that for the same earlier-mentioned $W_{0}=25$, which is a spending rate of $4 \%$, the optimal allocations to the CPI-linked fund are (generally, although not always) lower. The minimal ruin probabilities $\psi$ are uniformly higher in Table 3 compared to Table 2. The intuition is simple. If the CPI-linked fund is a 'worse' hedge for the retirement liabilities, the lifetime probability of ruin is higher, even under the most efficient or optimal investment strategy.

In Table 4, we present a different perspective on the results, by comparing the allocations as a function of perceived equity-market volatility. For example, a retiree who expects equities (investment fund) to earn $\mu=10 \%$ and market volatility to be of the order of $\sigma=20 \%$, should allocate $72 \%$ of his nest egg to CPI-linked bonds. However, if the volatility can be controlled and is reduced to a mere $\sigma=10 \%$ annualized, then the optimal allocation to the CPI-linked fund falls to $48 \%$. And, these results are obtained when the correlation between personal inflation and returns to the CPI-linked fund are high at $\rho_{\pi r}=95 \%$. When the correlation is much weaker at $\rho_{\pi r}=25 \%$, the optimal allocations to the CPI-linked fund drop to between $32 \%$ and $65 \%$. Note that despite the desire to minimize lifetime ruin probability, the allocation to the index-linked bond fund (ILBF) can be less than a third of the optimal portfolio.

Finally, in order to provide insight on how a dynamic (versus static) asset allocation strategy helps to lower the ruin probability $\psi$, we have plotted several key quantities in Figure 4. The underlying parameter values are the same as those in Table 2 with an expected equity return of $\mu=8 \%$. First, the minimum ruin probability $\psi$ as well as the ruin probabilities assuming a $100 \%$ allocation to the ILBF $(\alpha=1)$ or $100 \%$ allocation to the equity-based fund $(\alpha=0)$ are presented in Figure 4(a). Note how the optimal strategy results in a ruin probability that is lower than either of the extreme allocations. Then, the variation of the minimum ruin probability with age is plotted in Figure 4(b) and the dynamics of the optimal asset allocation ratio $\alpha^{*}$ at different ages is plotted in Figure 4(c). In order to gain some intuition for Figures 4(b) and 4(c) one should focus on the $x$-axis point where $w / l$ is 20 units. This represents an individual with assets worth 20 times their current level of consumption. At the age of 80 , this is a very fortunate situation because the ruin probability is less than $5 \%$ in Figure 4(b). However, at the age of 65 , this wealth-to-liability ratio induces a ruin probability of approximately $20 \%$. Obviously, as the wealth-toliability ratio increases, the entire vector of ruin probabilities declines, and reaches zero at approximately 50-to-1, Tables 5 and 6 .

Note in Figure 4(c) that the optimal allocation to the CPI-linked fund, which is represented in the $y$-axis, depends on age but asymptotes to about $80 \%$ when the wealth ratios are very high. At lower levels of wealth, the allocation to the CPI-linked fund is zero, especially at younger ages.

One of the main objectives of this study is to investigate the 'correlation impact.' In order to provide a graphical illustration, we have plotted $\alpha^{*}$ (asset allocation) and $\psi$ (ruin probability) against the wealth-to-liability ratio $w / l$ for three different correlation scenarios: $\rho_{\pi r}=0,0.4$ and 0.95 . The results are displayed in Figure 5. This allows us to directly observe (only) the impact of the correlation between the personal inflation rate and the returns to the CPI-linked fund. One of the more noticeable 

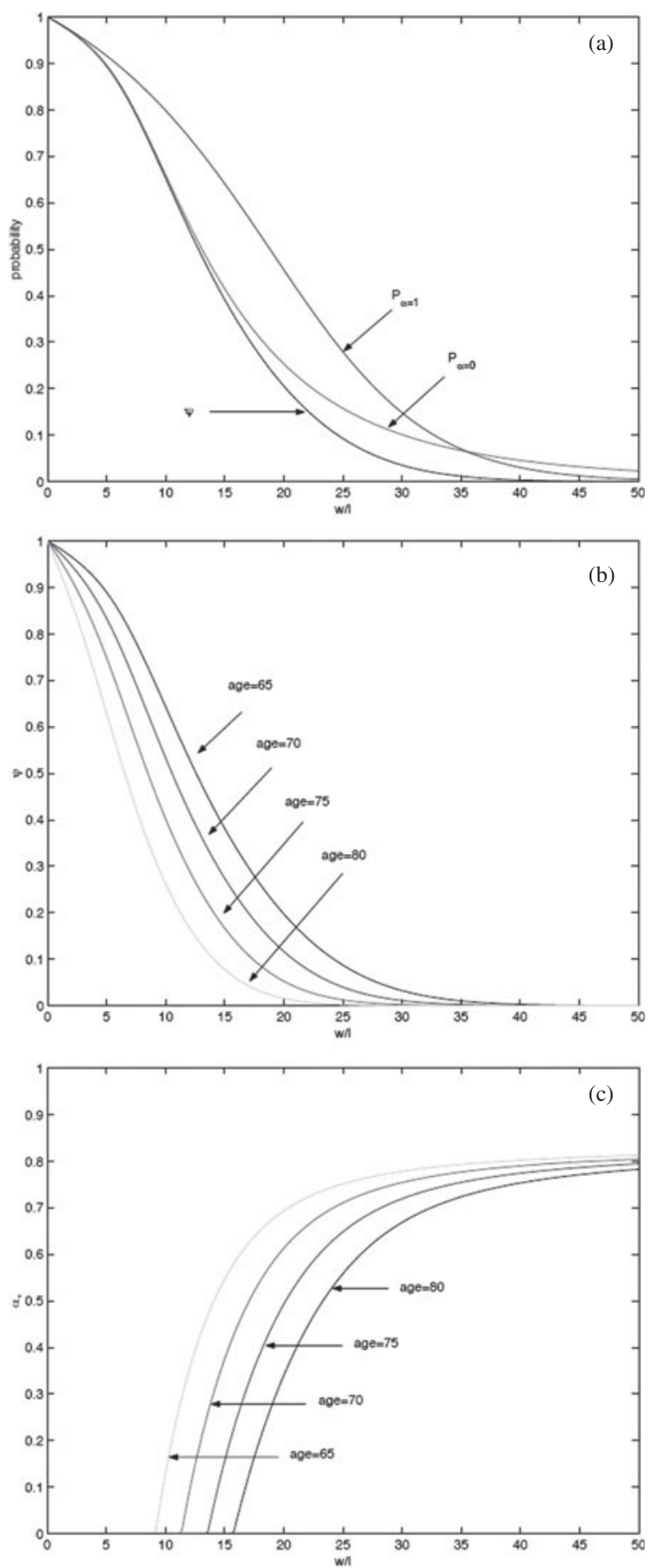

Figure 4. Ruin probability as function of wealth-toliability ratio. (a) Impact of strategy. (b) Impact of age. (c) Allocation to CPI fund as function of wealth-toliability ratio. 
Table 5. Optimal allocation to $\operatorname{ILBF}(\beta=0.5)$

\begin{tabular}{|c|c|c|c|c|c|c|c|c|}
\hline \multirow{3}{*}{$\begin{array}{l}\text { Expected } \\
\text { Investment } \\
\text { Fund return }(\%)\end{array}$} & \multirow{2}{*}{\multicolumn{2}{|c|}{$\begin{array}{c}W_{0}=18 \\
{ }_{0} / W_{0}=5.5 \%\end{array}$}} & \multirow{2}{*}{\multicolumn{2}{|c|}{$\begin{array}{c}W_{0}=20 \\
L_{0} / W_{0}=5.0 \%\end{array}$}} & \multirow{2}{*}{\multicolumn{2}{|c|}{$\begin{array}{c}W_{0}=22 \\
L_{0} / W_{0}=4.54 \%\end{array}$}} & \multirow{2}{*}{\multicolumn{2}{|c|}{$\begin{array}{c}W_{0}=25 \\
L_{0} / W_{0}=4.0 \%\end{array}$}} \\
\hline & & & & & & & & \\
\hline & $\alpha^{*}$ & $c^{*} / W_{0}$ & $\alpha^{*}$ & $c^{*} / W_{0}$ & $\alpha^{*}$ & $c^{*} / W_{0}$ & $\alpha^{*}$ & $c^{*} / W_{0}$ \\
\hline$\mu=6$ & 0.7647 & 0.0523 & 0.7600 & 0.0584 & 0.7562 & 0.0633 & 0.7517 & 0.0692 \\
\hline$\mu=7$ & 0.6620 & 0.0530 & 0.6532 & 0.0590 & 0.6460 & 0.0640 & 0.6374 & 0.0699 \\
\hline$\mu=8$ & 0.5587 & 0.0539 & 0.5458 & 0.0599 & 0.5353 & 0.0649 & 0.5227 & 0.0708 \\
\hline$\mu=9$ & 0.4549 & 0.0550 & 0.4381 & 0.0610 & 0.4243 & 0.0660 & 0.4077 & 0.0719 \\
\hline$\mu=10$ & 0.3507 & 0.0563 & 0.3298 & 0.0623 & 0.3128 & 0.0673 & 0.2924 & 0.0733 \\
\hline$\mu=11$ & 0.2459 & 0.0578 & 0.2211 & 0.0639 & 0.2009 & 0.0689 & 0.1767 & 0.0749 \\
\hline
\end{tabular}

Note: Assets that are not invested in the ILBF are allocated to Investment Fund with mean return $\mu$, and volatility $\sigma=20 \%$. The expected return from ILBF is $r=5 \%$, with volatility $\eta=8 \%$. Correlation between ILBF and Investment Fund return is $\rho_{r y}=0 \%$. Correlation between liability and Investment Fund return is $\rho_{\pi y}=25 \%$.

High $\left(\rho_{\pi r}=95 \%\right)$ correlation with spending/liabilities

High $(\xi=3 \%)$ volatility of spending/liabilities; $\pi=4 \%$

Table 6. Optimal allocation to $\operatorname{ILBF}(\beta=1.5)$

\begin{tabular}{|c|c|c|c|c|c|c|c|c|}
\hline \multirow{3}{*}{$\begin{array}{l}\text { Expected } \\
\text { Investment } \\
\text { Fund return }(\%)\end{array}$} & \multirow{2}{*}{\multicolumn{2}{|c|}{$\begin{array}{c}W_{0}=18 \\
L_{0} / W_{0}=5.5 \%\end{array}$}} & \multirow{2}{*}{\multicolumn{2}{|c|}{$\begin{array}{c}W_{0}=20 \\
L_{0} / W_{0}=5.0 \%\end{array}$}} & \multirow{2}{*}{\multicolumn{2}{|c|}{$\begin{array}{c}W_{0}=22 \\
L_{0} / W_{0}=4.54 \%\end{array}$}} & \multirow{2}{*}{\multicolumn{2}{|c|}{$\begin{array}{c}W_{0}=25 \\
L_{0} / W_{0}=4.0 \%\end{array}$}} \\
\hline & & & & & & & & \\
\hline & $\alpha^{*}$ & $c^{*} / W_{0}$ & $\alpha^{*}$ & $c^{*} / W_{0}$ & $\alpha^{*}$ & $c^{*} / W_{0}$ & $\alpha^{*}$ & $c^{*} / W_{0}$ \\
\hline$\mu=6$ & 0.6733 & 0.0607 & 0.6778 & 0.0659 & 0.6815 & 0.0701 & 0.6859 & 0.0752 \\
\hline$\mu=7$ & 0.4898 & 0.0614 & 0.4982 & 0.0666 & 0.5052 & 0.0708 & 0.5135 & 0.0759 \\
\hline$\mu=8$ & 0.3067 & 0.0624 & 0.3191 & 0.0676 & 0.3293 & 0.0718 & 0.3415 & 0.0769 \\
\hline$\mu=9$ & 0.1242 & 0.0638 & 0.1405 & 0.0689 & 0.1538 & 0.0732 & 0.1698 & 0.0782 \\
\hline$\mu=10$ & -0.0579 & 0.0655 & -0.0378 & 0.0707 & -0.0213 & 0.0749 & -0.0015 & 0.0799 \\
\hline$\mu=11$ & -0.2395 & 0.0676 & -0.2156 & 0.0727 & -0.1960 & 0.0769 & -0.1725 & 0.0819 \\
\hline
\end{tabular}

Note: Assets that are not invested in the ILBF are allocated to Investment Fund with mean return $\mu$ and volatility $\sigma=20 \%$. The expected return from ILBF is $r=5 \%$, with volatility $\eta=8 \%$. Correlation between ILBF and Investment Fund return is $\rho_{r y}=0 \%$. Correlation between liability and Investment Fund return is $\rho_{\pi y}=25 \%$.

High $\left(\rho_{\pi r}=95 \%\right)$ correlation with spending/liabilities

High $(\xi=3 \%)$ volatility of spending/liabilities; $\pi=4 \%$

results is the reversal of the asset allocation strategy - from safety to gambling - at a critical value of $w / l$. This is typical of all ruin minimization models, see Browne (1999), for example, where at some point the retiree decides to gamble (and hence volatility is welcomed.).

In sum, we do not expect the normative model developed here to drive actual asset allocation recommendations at retirement, especially given the rather restricted 

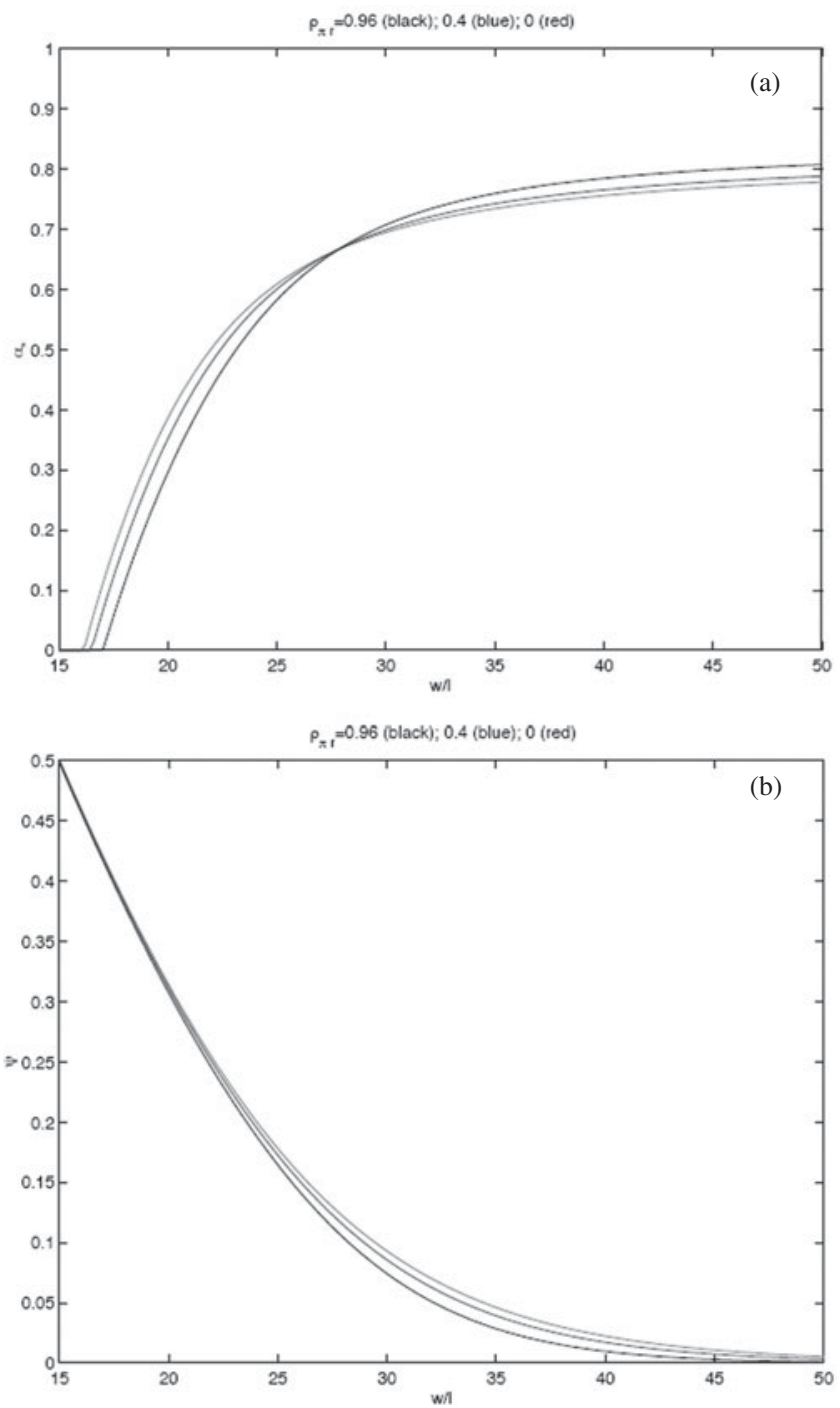

Figure 5. (a) CPI fund allocation as function of $W / L$ ratio: high, medium and zero correlation. (b) Ruin probability as function of $W / L$ ratio : $96 \%, 40 \%$ and $0 \%$ liability correlation.

nature of the assumed price dynamics (geometric Brownian motion) and investment choices. Furthermore, our selection of the minimum ruin criteria, as opposed to a more economically driven utility maximization criteria is meant to flush out the following point. Even the most risk averse preferences - i.e. 'my main goal is to never run out of money' - do not necessarily induce a complete allocation to the relatively safest asset, when the hedging and insurance are not perfect. To some readers this result might be obvious in an incomplete market, but we believe that it is worth emphasizing and illustrating in the context of inflation and the cost of living in retirement. There is no guarantee that an ILBF will hedge personal retirement liabilities. In our opinion, 
it should be treated as just another asset class in a liability-driven investment portfolio strategy, but with a unique set of risk, return and correlation parameters.

\section{Final words}

It is not widely known outside the specialized world of inflation connoisseurs and U.S. fed-watchers that inflation as measured for retirees (a.k.a. the elderly) is different from and mostly higher than the average inflation rate for the aggregate population. Indeed, in the U.S.A. the CPI has a lesser known relative, called the CPI-E (for the elderly) in which the sub-component weights are based on the consumption patterns of Americans above the age of 62. The CPI-E has consistently outpaced the broader CPI over the last 25 years that it has been measured, partially due to the greater weight placed on categories such as health-care expenses, long-term care facilities, the utilization of nursing services, etc. Although housing prices are also allocated greater weight in the CPI-E, it remains to be seen whether the recent decline in U.S. real estate will reverse the historical trend of CPI-E exceeding CPI-U (urban) and CPI-W (wage earner). Likewise, we do not address the persistent concern by some researchers and commentators that the CPI itself is biased downwards by hedonic adjustments and imputed rents, which would likely impact the CPI-E as well. One thing is for certain, there is a growing awareness that personal inflation rates for retirees are quite different from year-to-year changes in the CPI.

All of this suggests that investments linked to the CPI - such as retail mutual funds which contain various inflation-linked bonds (ILBF) - might not be a perfect hedge for individual retirees' unique cost of living. In order to focus on this idea in a more rigorous manner, this paper extends LRM techniques - recently employed by Moore and Young (2006), Young (2004), Albrecht and Maurer (2002) as well as Browne (1995) - to investigate the optimal asset allocation between a generic ILBF and a generic investment fund, for a retiree facing an exogenous liability stream that is imperfectly correlated to the returns on the CPI-linked fund. Our simple model trades off the benefits of an imperfect insurance hedge against the risky potential for investment growth.

Our results suggest that currently available CPI-linked funds - although they certainly are a large part of the optimal portfolio, especially for risk-averse investors as argued by Bodie and Clowes (2005) - should in fact be treated as just another asset class in the broad optimization problem, as opposed to a special or unique category. Practically speaking, retirees should (obviously) include CPI-linked investments in their portfolio universe, but not disproportionately so. In other words, it is very important to remember that inflation-linked assets might not keep up with the liability's inflation rate. So, in response to the question, which is the title of this paper, retirees should both hedge inflation risk and also worry about it.

\section{References}

Albrecht, P. and Maurer, R. (2002) Self-annuitization, consumption shortfall in retirement and asset allocation: the annuity benchmark. Journal of Pension Economics and Finance, 1(3): $269-288$. 
Amble, N. and Stewart, K. (1994) Experimental price index for elderly consumers. Bureau of Labor Statistics Monthly Labor Review, 117(5): 11-16.

Aziz, A., Katz, E. and Prisman, E. Z. (2001) Managing the risk of relative price changes by splitting index-linked bonds. Journal of Risk, 3(4): 69-88.

Bayraktar, E. and Young, V. R. (2007) Correspondence between lifetime minimum wealth and utility of consumption. Finance and Stochastics, 11(2): 213-236.

Bjork, T. (1998) Arbitrage Theory in Continuous Time. Oxford University Press, UK.

Bodie, Z. and Clowes, M. J. (2005) Worry-Free Investing: A Safe Approach to Achieving Your Lifetime Financial Goals. 1st edition, Financial Times/Prentice Hall, New Jersey.

Browne, S. (1995) Optimal investment policies for a firm with a random risk process: exponential utility and minimizing the probability of ruin. Mathematics of Operations Research, 20(4): 937-958.

Browne, S. (1999) The risk and reward of minimizing shortfall probability. Journal of Portfolio Management, 25(4): 76-85.

Cairns, A. J. G., Blake, D. and Dowd, K. (2006) Stochastic lifestyling: optimal dynamic asset allocation for defined contribution pension plans. Journal of Economic Dynamics and Control, 30: 843-877.

Campbell, J. and Viciera, L. (2002) Strategic Asset Allocation: Portfolio Choice for Long Term Investors. Oxford University Press, Oxford, UK.

Ernst, B., Cockburn, I., Douglas, C., Epstein, A. and Grilliches, Z. (1997) Is price inflation different for the elderly? A empirical analysis of prescription drugs. National Bureau of Economic Research (NBER) Working Paper, No. 6182.

Gao, J. (2009) Optimal investment strategy for annuity contracts under the constant elasticity of variance (CEV) model. Insurance: Mathematics and Economics, 45(1): 9-18.

Gupta, A. and Li, Z. (2007) Integrated optimal annuity planning with consumption-investment selections in retirement planning. Insurance: Mathematics and Economics, 41(1): 96-110.

Haberman, S. and Vigna, E. (2002) Optimal investment strategies and risk measures in defined contribution pension schemes. Insurance: Mathematics and Economics, 31(1): 35-69.

Hobijn, B. and Lagakos, D. (2003) Social Security and the Consumer Price Index for the Elderly. Current Issues in Economics and Finance, Volume 9, No. 5, Federal Reserve Bank of New York, pp. 1-6. http://www.newyorkfed.org/research/current_issues/ci9-5.pdf

Hoevenaars, P. M. M., Molenaar, R. D. J., Schotman, P. C. and Steenkamp, T. B. M. (2008) Strategic asset allocation with liabilities: beyond stocks and bonds. Journal of Economic Dynamics and Control, 32: 2939-2970.

Horneff, W. J., Maurer, R. H. and Stamos, M. Z. (2008) Lifecycle asset allocation with annuity markets. Journal of Economic Dynamics and Control, 32: 3590-3612.

House of Representatives (2001) Consumer Price Index for the Elderly Consumers Act, H.R. 2035 (107th Congress).

Huang, H., Milevsky, M. A. and Wang, J. (2004) Ruined moments in your life: how good are the approximation. Insurance: Economics and Mathematics, 34: 421-447.

Ibbotson, R. G., Milevsky, M. A., Chen, P. and Zhu, K. (2007) Lifetime Financial Advice: Human Capital, Asset Allocation and Insurance. CFA Institute, Charlottesville, VA, USA.

Jarrow, R. and Yildirim, Y. (2003) Pricing treasury inflation protected securities and relative derivatives using HJM model. Journal of Financial and Quantitative Analysis, 38(2): 337-358.

Jennings, W. (2006) Disaggregated TIPS: the case for disaggregating inflation linked bonds into bonds linked to narrower CPI components. Journal of Pension Economics and Finance, 5(3): 325-343.

Kothari, S. P. and Shanken, J. (2004) Asset allocation with inflation-protected bonds. Financial Analysts Journal, 60(1): 54-70.

Merton, R. C. (1971) Optimum consumption and portfolio rules in a continuous time model. Journal of Economic Theory, 3(December): 373-413.

Milevsky, M. A. (2006) The Calculus of Retirement Income: Financial Models for Life Insurance and Pension Annuities. Cambridge: Cambridge University Press. 
Milevsky, M. A. and Robinson, C. (2000) Self-annuitization and ruin in retirement. North American Actuarial Journal, 4(4): 112-129.

Moore, K. S. and Young, V. R. (2006) Optimal and simple: nearly optimal rules for minimizing the probability of financial ruin in retirement. North American Actuarial Journal, 10(4): $145-162$.

Robinson, C. and Tahani, N. (2007) Sustainable retirement income for the socialite, the gardener and the uninsured. Atkinson College Working Paper. SSRN. Available at http://ssrn.com/abstract $=989165$

Wang, Y. (2009) Quantile hedging for guaranteed minimum death benefits. Insurance: Mathematics and Economics, 45(3): 449-458.

Young, V. R. (2004) Optimal investment strategy to minimize the probability of lifetime ruin. North American Actuarial Journal, 8(4): 106-126.

\section{Appendix - Detailed derivation and solution}

\section{A.1 Derivation of the HJB}

The derivation is based on the method in Björk (1998, chapter 14). Assume an individual of age $a$ at time zero. At any time $t$ the individual aged $a+t$ continues the optimal asset allocation strategy within the range $0 \leqslant \alpha \leqslant 1$ if they survive until $t+h$. On the other hand, if the individual aged $a+t$ dies before time $t+h$, then the probability of ruin is zero. Let $\phi(w, l, t)$ denote the minimum ruin probability, i.e.

$$
\phi(w, l, t)=\min _{0 \leqslant \alpha_{t} \leqslant 1} \operatorname{Pr}\left[\tau_{0}<\tau_{\mathrm{d}} \mid W_{t}=w, L_{t}=l, \tau_{\mathrm{d}}>t\right] .
$$

Therefore,

$$
\phi(w, l, t) \leqslant E\left[\phi\left(W_{t+h}, L_{t+h}, t+h\right) \mid W_{t}=w, L_{t}=l\right]_{h} p_{a+t}+E\left[0 \mid W_{t}=w, L_{t}=l\right]_{h} q_{a+t},
$$

where the equality holds if and only if the optimal strategy is used. Here the symbols ${ }_{h} p_{a+t}$ and ${ }_{h} q_{a+t}:=1-{ }_{h} p_{a+t}$ are standard actuarial notation for the probabilities of surviving and dying between the time period $h$ for an individual aged $a+t$, given by

$$
{ }_{h} p_{a}=\mathrm{e}^{-\int_{0}^{h} \lambda_{a+s} \mathrm{~d} s}
$$

where $\lambda_{t}$ is the instantaneous hazard rate of the force of mortality. Now, let $A$ denote the operator defined as follows:

$$
\begin{aligned}
A f(w, l, t)= & f_{t}+[\alpha r w+(1-\alpha) \mu w-l] f_{w} \\
& +\frac{1}{2}\left\{(\alpha \eta)^{2}+[(1-\alpha) \sigma]^{2}+2 \alpha(1-\alpha) \rho_{r y} \eta \sigma\right\} w^{2} f_{w w} \\
& +\pi l f_{l}+\frac{1}{2}(\xi l)^{2} f_{l l}+\left[\alpha \rho_{\pi r} \eta+(1-\alpha) \rho_{\pi y} \sigma\right] \xi w l f_{w l},
\end{aligned}
$$

where $f_{t}, f_{w}, f_{l}$, etc. denote derivatives with respect to time, wealth and liability, respectively. 
Using Ito's lemma on the function $\phi$, we have

$$
\begin{aligned}
\phi\left(W_{t+h}, L_{t+h}, t+h\right)= & \phi(w, l, t)+\int_{t}^{t+h} A \phi\left(w_{s}, l_{s}, s\right) \mathrm{d} s \\
& +\int_{t}^{t+h} \phi_{w}\left(w_{s}, l_{s}, s\right)\left[\alpha \eta w_{s} \mathrm{~d} B_{s}^{r}+(1-\alpha) \sigma w_{s} \mathrm{~d} B_{s}^{y}\right] \\
& +\int_{t}^{t+h} \phi_{l}\left(w_{s}, l_{s}, s\right) \xi l \mathrm{~d} B_{s}^{\pi} .
\end{aligned}
$$

Combining equations (12), (14) and (15), we obtain

$$
\phi(w, l, t) \leqslant{ }_{h} p_{a+t} E^{w, l, t}\left[\phi(w, l, t)+\int_{t}^{t+h} A \phi\left(W_{s}, L_{s}, s\right) \mathrm{d} s\right],
$$

or

$$
\phi(w, l, t)_{h} q_{a+t} \leqslant{ }_{h} p_{a+t} E^{w, l, t}\left[\int_{t}^{t+h} A \phi\left(W_{s}, L_{s}, s\right) \mathrm{d} s\right] .
$$

Taking the limit of $h \rightarrow 0$ and using $\lim _{h \rightarrow 0} h^{-1}{ }_{h} q_{a+t}=\lambda_{a+t}$, we obtain

$$
\phi(w, l, t) \lambda_{a+t} \leqslant A \phi(w, l, t)
$$

and the equality holds when the optimal strategy is used, which is either given by the first-order condition or the boundary values $\alpha=0$ or 1 . Thus, we obtain the HJB equation

$$
\phi(w, l, t) \lambda_{a+t}=\min _{0 \leqslant \alpha \leqslant 1}\{A \phi(w, l, t)\} .
$$

The boundary conditions are

$$
\phi(\infty, l, t)=0, \quad \phi(0, l, t)=1, \quad \phi(w, 0, t)=0, \quad \phi(w, \infty, t)=1 .
$$

Assuming an infinite time horizon, the terminal condition is

$$
\phi(w, l, \infty)=0 .
$$

When the mortality rate $\lambda_{a+t}$ is a constant, the infinite time horizon case leads to a time-independent version of (19) by dropping the term $\phi_{t}$. However, this is not the case (for realistic biological mortality), where the variable $\lambda_{a+t}$ is time dependent and the solution $\phi$ is therefore also time dependent. In this case, time is equivalent to age, and we can rewrite the HJB equation (19) using age $a$ as the time variable

$$
\lambda_{a} \phi=\phi_{a}+\min _{0 \leqslant \alpha \leqslant 1} H,
$$


where

$$
\begin{aligned}
H:= & {[\alpha r w+(1-\alpha) \mu w-l] \phi_{w}+\pi l \phi_{l} } \\
& +\frac{1}{2}\left\{(\alpha \eta)^{2}+[(1-\alpha) \sigma]^{2}+2 \alpha(1-\alpha) \rho_{r y} \eta \sigma\right\} w^{2} \phi_{w w} \\
& +\frac{1}{2}(\xi l)^{2} \phi_{l l}+\left[\alpha \rho_{\pi r} \eta+(1-\alpha) \rho_{\pi y} \sigma\right] \xi w l \phi_{w l} .
\end{aligned}
$$

The boundary conditions are still:

$$
\phi(\infty, l, a)=0, \quad \phi(0, l, a)=1, \quad \phi(w, 0, a)=0, \quad \phi(w, \infty, a)=1, \quad \phi(w, l, \infty)=0 .
$$

\section{A.2 Solution procedure}

By introducing a similarity variable $x=w / l$, which is the ratio of wealth to the liabilities, it can be shown that the now two-dimensional equation $\psi(x, a)=\phi(w, l, a)$ satisfies

$$
\lambda_{a} \psi=\psi_{a}+\min _{0 \leqslant \alpha \leqslant 1} H
$$

where

$$
\begin{aligned}
H:= & \frac{1}{2}\left\{\left[\alpha^{2} \eta^{2}+(1-\alpha)^{2} \sigma^{2}+2 \alpha(1-\alpha) \rho_{r y} \eta \sigma\right]+\xi^{2}-2\left[\alpha \rho_{\pi r} \eta+(1-\alpha) \rho_{\pi y} \sigma\right] \xi\right\} x^{2} \psi_{x x} \\
& +\left\{[\alpha r x+(1-\alpha) \mu x-1-\pi x]+\xi^{2} x-\left[\alpha \rho_{\pi r} \eta+(1-\alpha) \rho_{\pi y} \sigma\right] \xi x\right\} \psi_{x},
\end{aligned}
$$

or

$$
\lambda_{a} \psi=\psi_{a}+H^{*}
$$

where

$$
\begin{aligned}
H^{*}:= & \frac{1}{2}\left\{\left[\alpha^{* 2} \eta^{2}+\left(1-\alpha^{*}\right)^{2} \sigma^{2}+2 \alpha^{*}\left(1-\alpha^{*}\right) \rho_{r y} \eta \sigma\right]+\xi^{2}-2\left[\alpha^{*} \rho_{\pi r} \eta+\left(1-\alpha^{*}\right) \rho_{\pi y} \sigma\right] \xi\right\} x^{2} \psi_{x x} \\
& +\left\{\left[\alpha^{*} r x+\left(1-\alpha^{*}\right) \mu x-1-\pi x\right]+\xi^{2} x-\left[\alpha^{*} \rho_{\pi r} \eta+\left(1-\alpha^{*}\right) \rho_{\pi y} \sigma\right] \xi x\right\} \psi_{x} .
\end{aligned}
$$

The boundary conditions are

$$
\psi(0, a)=1, \quad \psi(\infty, a)=0, \quad \psi(x, \infty)=0 .
$$

To determine $\alpha^{*}$, we first apply the first-order condition $H_{\alpha}=0$, which yields

$$
\alpha^{*}=-\frac{\left(\rho_{\pi y} \sigma-\rho_{\pi r} \eta\right) \xi+r-\mu}{\eta^{2}+\sigma^{2}-2 \rho_{r y} \eta \sigma} \frac{\psi_{x}}{x \psi_{x x}}-\frac{\sigma\left(\rho_{r y} \eta-\sigma\right)+\left(\rho_{\pi y} \sigma-\rho_{\pi r} \eta\right) \xi}{\eta^{2}+\sigma^{2}-2 \rho_{r y} \eta \sigma} .
$$

As we will demonstrate in the appendix, under certain conditions, $\psi(x, a)$ will not be a strictly convex or concave function of $x$. Thus, the value of $\alpha^{*}$ cannot be determined 
only by the first-order optimality condition. Since

$$
H_{\alpha \alpha}=\left(\eta^{2}+\sigma^{2}-2 \rho_{r y} \eta \sigma\right)^{2} x^{2} \psi_{x x}
$$

and $\psi$ is not convex, $H_{\alpha \alpha}$ can change signs. Therefore, we need both the first- and second-order conditions to determine the value of $\alpha^{*}$ as follows:

- If $H_{\alpha \alpha}>0$ and $\alpha^{*}$ given by (30) satisfies $0 \leqslant \alpha^{*} \leqslant 1$, then that is the value for $\alpha^{*}$.

- If $H_{\alpha \alpha}>0$ and $\alpha^{*}$ given by (30) satisfies $\alpha^{*}>1$, then $\alpha^{*}=1$.

- If $H_{\alpha \alpha}>0$ and $\alpha^{*}$ given by (30) satisfies $\alpha^{*}<0$, then $\alpha^{*}=0$.

- If $H_{\alpha \alpha} \leqslant 0$, we need to compare $H$ at $\alpha=0$ and $\alpha=1$ and choose the $\alpha^{*}$ value that gives the smaller $H$.

In order to solve equation (27) numerically, we need to truncate the domain in $x$ as well as $y$ and replace the boundary conditions in (29) by

$$
\psi(0, a)=1, \quad \psi\left(x_{\max }, a\right)=0, \quad \psi\left(x, a_{\max }\right)=0,
$$

where $x_{\max }$ and $a_{\max }$ are relatively large numbers. The computational results presented in this paper are obtained by choosing $x_{\max }=200$ and $a_{\max }=125$, based on the observation that further increasing the size of the domain produces almost identical solutions.

There are two possible ways of solving (27), one by discretizing the time derivative $\psi_{a}$ explicitly, whereas the other by using an implicitly method. In both cases, we discretize $a$ as $a_{n}=a_{0}+n \delta a$ for $n=0,1, \ldots, N$, where $\delta a=\left(a_{\max }-a_{0}\right) / N, a_{0}$ is the current age of the retiree. Furthermore, we set up a grid in $x$, using $x_{j}=j \delta x$ for $j=0$, $1, \ldots, J$, where $\delta x=x_{\max } / J$. Let $\psi_{j}^{(n)}$ be an approximation of $\psi\left(x_{j}, a_{n}\right)$, in the explicit method, we use

$$
\psi_{a}\left(x_{j}, a_{n}\right) \approx \frac{\psi_{j}^{(n+1)}-\psi_{j}^{(n)}}{\delta a}
$$

while

$$
\psi_{a}\left(x_{j}, a_{n+1}\right) \approx \frac{\psi_{j}^{(n+1)}-\psi_{j}^{(n)}}{\delta a}
$$

is used for the implicit method.

\section{A.2.1 Explicit method}

In this case, equation (27) is approximated by

$$
\begin{aligned}
\psi_{j}^{(n+1)}= & \psi_{j}^{(n)}+\delta a F\left(\psi_{j}^{(n)}\right), \\
F\left(\psi_{j}^{(n)}\right)= & -\lambda_{a} \psi_{j}^{(n)} \\
& +\frac{1}{2}\left\{\left[\alpha^{*}, j^{2} \eta^{2}+\left(1-\alpha^{*}, j\right)^{2} \sigma^{2}+2 \alpha^{*}, j\left(1-\alpha^{*}, j\right) \rho_{r y} \eta \sigma\right]\right. \\
& \left.+\xi^{2}-2\left[\alpha^{*}, j \rho_{\pi r} \eta+\left(1-\alpha^{*}, j\right) \rho_{\pi y} \sigma\right] \xi\right\} x^{2} \psi_{x x}^{(n)}\left(x_{j}\right) \\
& +\left\{\left[\alpha^{*}, j r x+\left(1-\alpha^{*}, j\right) \mu x_{j}-1-\pi x_{j}\right]+\xi^{2} x_{j}\right. \\
& \left.-\left[\alpha^{*}, j \rho_{\pi r} \eta+\left(1-\alpha^{*}, j\right) \rho_{\pi y} \sigma\right] \xi x_{j}\right\} \psi_{x}^{(n)}\left(x_{j}\right),
\end{aligned}
$$


where

$$
\psi_{x}^{(n)}\left(x_{j}\right)=\frac{\psi_{j+1}^{(n)}-\psi_{j-1}^{(n)}}{2 \delta x}, \quad \psi_{x x}^{(n)}\left(x_{j}\right)=\frac{\psi_{j+1}^{(n)}+\psi_{j-1}^{(n)}-2 \psi_{j}^{(n)}}{\delta x^{2}} .
$$

In general, the value of $\alpha^{*}, j$ can be determined using both the first- and second-order optimality conditions, as described earlier. However, owing to the explicit nature of the method, we can use a simpler approach as follows.

Let $\psi_{j}^{(n, *)}$ denote the solution obtained using (36) and the first-order condition (30), $\psi_{j}^{(n, 0)}$ and $\psi_{j}^{(n, 1)}$ the solution of (36) using $\alpha=0$ or $\alpha=1$. We choose the final solution as

$$
\psi_{j}^{(n)}=\min \left\{\psi_{j}^{(n, *)}, \psi_{j}^{(n, 0)}, \psi_{j}^{(n, 1)}\right\} .
$$

This method is conceptually simple and easy to implement. However, it is not efficient as small $\delta a$ has to be used because of stability constraint associated with the explicit method.

\section{A.2.2 Implicit method}

Alternatively, we can use an implicit method by approximating equation (27) as

$$
\begin{gathered}
\psi_{j}^{(n+1)}=\psi_{j}^{(n)}+\delta a F\left(\psi_{j}^{(n+1)}\right), \\
F\left(\psi_{j}^{(n+1)}\right)=-\lambda_{a} \psi_{j}^{(n+1)}+\frac{1}{2}\left\{\left[\alpha^{*}, j^{2} \eta^{2}+\left(1-\alpha^{*}, j\right)^{2} \sigma^{2}+2 \alpha^{*}, j\left(1-\alpha^{*}, j\right) \rho_{r y} \eta \sigma\right]\right. \\
\left.+\xi^{2}-2\left[\alpha^{*}, j \rho_{\pi r} \eta+\left(1-\alpha^{*}, j\right) \rho_{\pi y} \sigma\right] \xi\right\} x_{j}^{2} \psi_{x x}^{(n+1)}\left(x_{j}\right) \\
+\left\{\left[\alpha^{*}, j r x_{j}+\left(1-\alpha^{*}\right) \mu x_{j}-1-\pi x_{j}\right]+\xi^{2} x_{j}\right. \\
\left.-\left[\alpha^{*}, j \rho_{\pi r} \eta+\left(1-\alpha^{*}, j\right) \rho_{\pi y} \sigma\right] \xi x_{j}\right\} \psi_{x}^{(n+1)}\left(x_{j}\right),
\end{gathered}
$$

where

$$
\psi_{x}^{(n+1)}\left(x_{j}\right)=\frac{\psi_{j+1}^{(n+1)}-\psi_{j-1}^{(n+1)}}{2 \delta x}, \quad \psi_{x x}^{(n+1)}\left(x_{j}\right)=\frac{\psi_{j+1}^{(n+1)}+\psi_{j-1}^{(n+1)}-2 \psi_{j}^{(n+1)}}{\delta x^{2}} .
$$

The simple approach used in the explicit method is not applicable here. Instead, we have to use both the first and second optimality condition and apply the procedure described earlier to determine $\alpha^{*}, j$. In a fully implicit method, we need to apply the iterative method to find the solution owing to the non-linear nature of the problem. In this paper, we use a semi-implicit version by computing $\alpha^{*}, j$ using $\psi_{j}^{(n)}$ instead of $\psi_{j}^{(n+1)}$. By comparison, this semi-implicit method is simpler than the fully implicit one and much more efficient than the explicit method since a relatively large $\delta a$ can be used for the computation.

Finally, as we alluded to earlier, when the investment portfolio consists of a riskfree asset and consumption rate is a constant, it can be shown that the ruin can be avoided under certain conditions, and the probability of ruin, when it is not zero, is a convex function of the wealth, as shown by Young (2004). However, when the portfolio consists of only risky assets, it may not be possible to eliminate ruin completely. 
Furthermore, the probability of ruin may not be a convex function of the wealth; see Huang et al. (2004) for the case with one risky asset and a constant rate of consumption. The situation considered in this paper is more complicated. When the liability and the risky assets are completely correlated, it is possible to avoid ruin when the wealth level relative to liability is sufficiently high. On the other hand, when the risky assets and liability are not perfectly correlated, the situation is not as simple. In order to see this, we restrict ourselves to the case when the age if relatively small, so that both the mortality rate and the change of ruin probability with time/age is small. In other words, the Hamiltonian $H^{*} \approx 0$ in equation (28). When $x$ is small, from equation (28), it can be seen that parameter of the second-order derivative remains positive while that of first derivative is approximately -1 . Since $\psi_{x}<0$, we must have $\psi_{x x}<0$, i.e., $\psi$ is convex for small $x$. For large $x$, on the other hand, the coefficient of $\psi_{x}$ is approximately

$$
\left\{\alpha^{*} r+\left(1-\alpha^{*}\right) \mu+\xi^{2}-\left[\alpha^{*} \rho_{\pi r} \eta+\left(1-\alpha^{*}\right) \rho_{\pi y} \sigma\right] \xi-\pi\right\} x,
$$

which could be positive or negative. When

$$
\pi+\left[\alpha^{*} \rho_{\pi r} \eta+\left(1-\alpha^{*}\right) \rho_{\pi y} \sigma\right] \xi<\alpha^{*} r+\left(1-\alpha^{*}\right) \mu+\xi^{2}
$$

for any $0 \leqslant \alpha^{*} \leqslant 1$, the coefficient of $\psi_{x}$ is positive. Since the coefficient of $\psi_{x x}$ is also positive, $\psi_{x x}$ must be positive, i.e., $\psi$ is now a concave function of $x$ (scaled wealth). 